\title{
STUDENT MENTOR'S IDEAL FEATURES: PEER CHOICE
}

\author{
Madalena Cunha ${ }^{1}, \&$ Nuno Campos ${ }^{2}$ \\ ${ }^{I}$ Nursing, UICISA:E, SIGMA - Phi Xi Chapter, Superior School of Health, Polytechnic Institute of Viseu \\ and to the CIEC, University of Minho (Portugal) \\ ${ }^{2}$ Superior School of Health, Polytechnic Institute of Viseu (Portugal)
}

\begin{abstract}
Introduction: A student mentor is someone who shares his or her knowledge with a less experienced colleague in order to help the other developing his or her full academic potential by providing him/ her with the right guidance and support during his learning, social and academic integration processes.

Objective: To assess the features higher education students consider to be the most effective characteristics their Student Peer Mentor should possess.

Method: A descriptive-exploratory study, with a cross-sectional focus, involving a sample of 306 higher education health students, with a mean age of $21.15( \pm 3,540)$ years. $81.7 \%$ of the participants are female. Data collection was achieved using Cunha's Ideal Mentor Faces Scale (2017) with images adapted from Botas, Gabriel \& Welling, (1997/1998).

Results: Results show that $61.8 \%$ of the students surveyed would like to be student mentors and that most participants (54.2\%) look at their ideal mentor as someone who possesses positive features, while $12,1 \%$ of the participants would choose for their ideal mentor a student whose features might suggest the existence of a risk profile. Finally, and paradoxically, $33.7 \%$ of them would choose a student mentor who tends to exhibit certain negative features.

Positive characteristics were granted the highest mean values. Those values ranged between Satisfied (68\%), Tranquil (78.1\%); Optimistic (85\%); Confident (88.2\%) and Interested (87.9\%).

Conclusions: Results suggest that higher education students value the existence of student mentors with positive features/characteristics and realize that their existence is of great pedagogical importance. Therefore, there is now a greater need to ask higher education students to participate in Mentoring programs implemented with the support of second or third year Student Mentors who, on a voluntary basis, using their experiences and academic experiences can supervise incoming first year students (Mentee Students) in order to facilitate their integration and their adaptation to the different dimensions (pedagogical, scientific, social and any other) of the academic environment.
\end{abstract}

Keywords: Students, higher education, features, student mentor.

\section{Introduction}

The transition to higher education is regarded as a facilitating factor for new experiences. It is an early stage of a life project that may provoke confusing feelings that could cause students to behave differently. It is clearly a moment that requires adjustments and adaptations so that students can have a good academic performance. The shift from secondary education to higher education causes challenges for students which will have an impact on the way existing roles, routines, interpersonal relationships are transformed and on the way they perceive themselves and perceive their new. In order for students' adaptation to all the changes that are part of higher education to be effective, they must gain skills that will enable them to mobilize their personal resources and contexts. Among those resources, the importance of self-efficacy, a complex concept that explains the ability to cope with the surrounding environment, should be highlighted. This is a personal perspective through which the student tries to cope with the academic community and that will allow him to have an optimistic and positive emotional state (Carr, Perrell \& Recchia, 2016).

This is the right context for the student mentor to emerge as a type of student who can assist other students so they may develop their self-efficacy and find the right coping strategies, for if students do not have these skills, they may find it difficult to adapt to new and challenging events or situations they will have to face in the academic environment.

Mentor is the term generally used to describe a more experienced individual who is responsible for guiding and advising (Karkowska, 2015). "Mentoring" is a term generally employed to describe a relationship between a less experienced person, called mentee or protégé, and a more experienced person 
known as a mentor. Traditionally, mentoring was viewed as a dyadic, face-to-face, long-term relationship between a supervisory adult and a novice student that fosters the mentee's professional, academic or personal development (Karkowska, 2015).

In the context of education, the role of the student mentor can become an excellent tool for the mentee's personal and academic growth, as well as an effective means that will help them adapt to their academic life (Carr, Perrell \& Recchia, 2016). That way, the same authors report that mentorship is based on a short-term collaborative relationship between two students achieved through the development of a relationship between an experienced student and a student who has just joined a higher education institution. The student mentor can negotiate with his mentee an action plan whose aims are to provide him with the right interpersonal skills and to provide him the right human, academic, social and pedagogical support. A study conducted in 2014 by Jay, Park, Deirdre \& Doug (2016) with undergraduate medical students from the University of Calgary's Cumming School of Medicine indicates that students who were assigned a mentors show a greater sense of well-being and greater satisfaction with their academic life compared to students who are not mentees. The study also revealed that $58 \%$ (54 of 93) of the students reported having an informal mentor. Supporting coping strategies seems to be an effective predictor of higher education students' well-being. (Cunha, Duarte, André, Sequeira, Castro-Molina, Mota et al, 2017).

In view of the above, this article presents the results of the study, bearing in mind the following objective: to evaluate the ideal features that mentees consider their mentor students should possess.

\section{Methods}

The current cross-sectional descriptive-exploratory study involving a sample of 306 higher education health students.

\subsection{Participants}

Non-probability sampling was the sampling technique used in this study. The participants' age (they should be 18 or older) and the fact that they had to be higher education students were the criteria designed for the sample. The participants ' ages ranged between 18 years old and 42 years old, with a mean age of $21.15( \pm 3.540)$ years. $81.7 \%(n=250)$ of the participants were female.

\subsection{Data collection instruments}

The data collection instrument used was Cunha's Ideal Mentor Faces Scale (2017) with images adapted from Botas, Gabriel \& Welling (1997). The Ideal Mentor Faces Scale figures were coded as follows: from 1 to 30, in which 1 stands for aggressive, 2 for anxious, (...) 30 stands for self-conscious. The code designed for each image is as follow: 1-aggressive; 2-anxious; 3-shy; 4-arrogant; 5-tranquil; 6-bored; 7-confident; 8-euphoric; 9-enraged; 10-desperate; 11-exhausted; 12-frustrated; 13-guilted; 14-hangovered; 15-hysterical; 16-indifferent; 17-naive; 18- Interested 19-intoxicated; 20-lonely; 21-in love; 22-meditative; 23-miserable; 24-negative; 25-optimistic; 26-satisfied; 27-grumpy; 28-excited; 29-disgusted; 30- self-conscious). (Cf. Figure 1).

The faces participants considered more positive were: 5-tranquil; 7-confident 18-interested; 25 - optimistic; 26-satisfied. The Student Mentors' most appropriate profile mirrors situations in which the participants have selected 4 or 5 of the pictures with more positive features; risk profiles reflect situations in which the participants have selected only 2 to 3 figures they consider to be positive; negative profiles are represented by situations where the participants selected 0 or 1 picture among those they consider positive.

\subsection{Procedures}

The study obtained a favorable opinion from the Ethics Committee ( ${ }^{\circ}$ 3/2017) of the Higher Education Institution involved and the collection of data was authorized by the Presidents of the different schools that represent the functional units of a polytechnic Institute located in the northern region of Portugal. The students have participated voluntarily and, after they were provided with all the information they needed on the research project and the research protocols, gave their informed consent.

Statistical treatment of the data was performed using the Statistical Package for Social Sciences (SPSS) version 24.0.

\section{Results}

The results for the overall sample obtained using Cunha's Ideal Mentor Faces Scale (EFMI), (2017) show the mean values calculated for each feature selected as being the most suited for the students' ideal student mentor. These are the mean values found: 1 - aggressive $(0.3 \%)$; 2 -anxious $(1.3 \%)$; 3-shy $(0.3 \%)$; 4-arrogant $(0.3 \%)$; 5-tranquil $(78,1 \%)$; 6-bored $(0.3 \%)$; 7-confident $(88.2 \%)$; 8 -euphoric $(3.3 \%)$; 9-enraged $(0.3 \%) ; 10$-desperate $(0.3 \%) ; 11$-exhausted $(0.3 \%) ; 12$-frustrated $(0.3 \%)$; 13 - guilted $(0.3 \%)$; 14-hangovered $(0.3 \%) ; 15$-hysterical $(0.3 \%) ; 16$-indifferent $(0.7 \%)$; 17-naive $(0.7 \%)$; 
18 -interested $(87.9 \%) ; 19$-intoxicated $(0.3 \%) ; 20$-lonely $(0.7 \%) ; 21$-in love $(11.8 \%) ; 22$-meditative $(10.1 \%) ; 23$-miserable $(0.3 \%) ; 24$-negative $(0.3 \%) ; 25$-optimistic $(85.0 \%) ; 26$-satisfied $(68.0 \%)$; 27-grumpy $(0.3 \%)$; 28 -excited $(7.5 \%) ; 29$-disgusted $(0.3 \%) ; 30$-self-conscious $(0.1 \%)$.

Figure 1. Cunha's ldeal Mentor Faces Scale (2017).
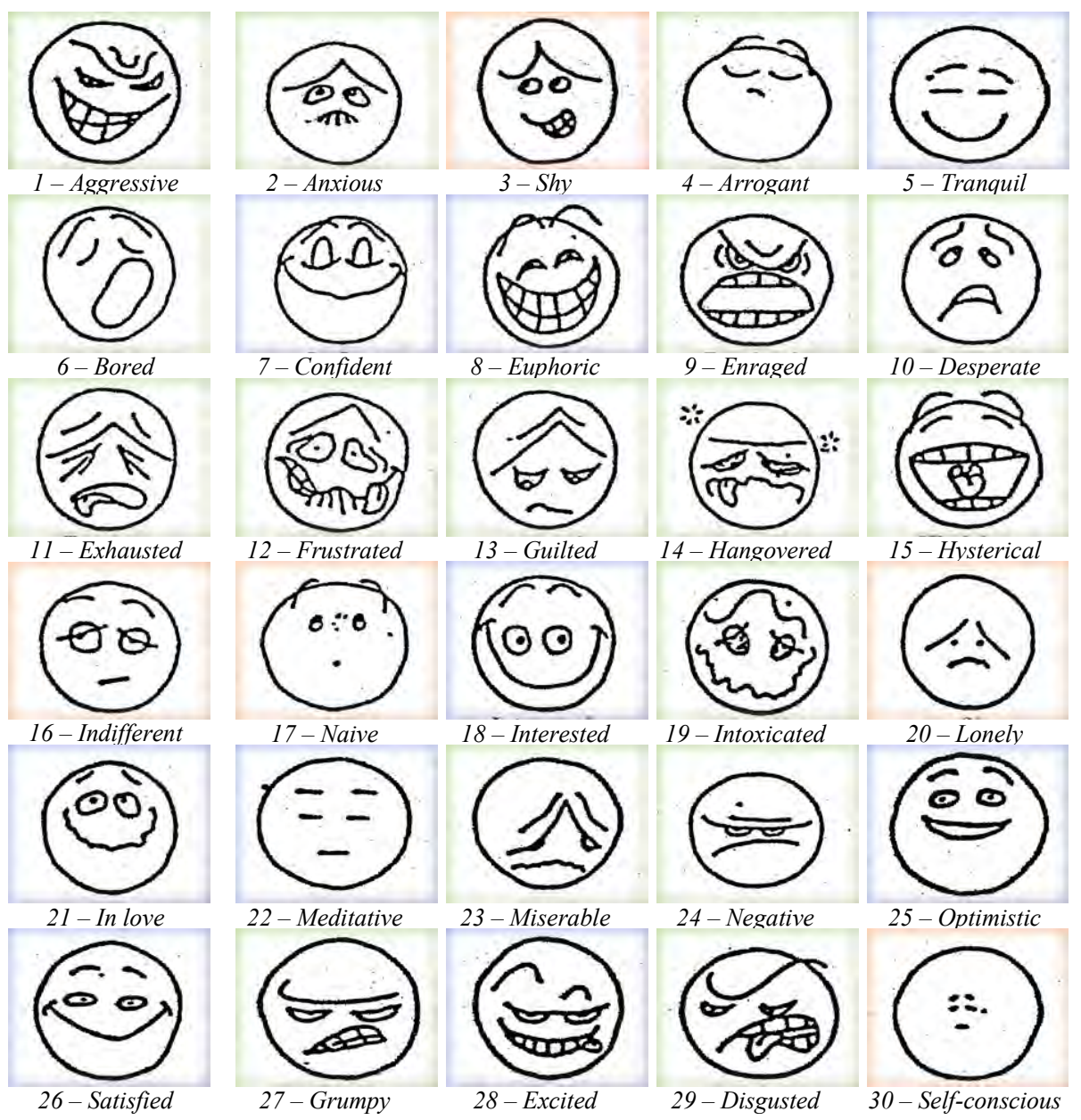

The features/profiles considered positive were granted the highest mean values that ranged between: (68.0\%) 26-satisfied; (78.1\%) 5-tranquil; (85.0\%) 25-optimistic; $(88.2 \%)$ 7-confident and (87.9\%) 18-interested. Most students (54.2\%) selected positive features as the best suited for their ideal student mentor. Both genders made similar choices $(54.4 \%$ for female students and $53,6 \%$ for male students). As far as student mentors' ideal features are concerned, evidence clearly showed that the choice of highly suitable features prevails among a large percentage of the participants, whether they are female or male $(54.2 \%)$. $54 \%$ of this overall value corresponds to a choice among female students while $53.6 \%$ reflect male students' choice. $12.1 \%$ of the students assign suitable features to their hypothetical mentor. This situation relates especially to female participants $(12.4 \%)$. Finally, $33.7 \%$ of the participants have selected poorly suited features for their ideal mentor. $33.2 \%$ of those students were female and $35.7 \%$ were male. However, there are no statistically significant differences between genders when it comes to choose the right features for their ideal mentor (Cf. Table 1).

Table 1. Features students consider the most suitable for their ideal mentor according to participants.

\begin{tabular}{|c|c|c|c|c|c|c|c|c|c|c|}
\hline Gender & \multicolumn{2}{|c|}{ Female } & \multicolumn{2}{|c|}{ Male } & \multicolumn{2}{|c|}{ Total } & \multicolumn{2}{|c|}{ Residual } & \multirow[b]{2}{*}{$\mathbf{X}^{2}$} & \multirow[b]{2}{*}{$\mathbf{p}$} \\
\hline Ideal Mentor features & $\begin{array}{c}n^{0} \\
(25)\end{array}$ & $\begin{array}{c}\% \\
(\mathbf{8 1 . 7}) \\
\end{array}$ & $\begin{array}{c}n^{\circ} \\
(56)\end{array}$ & $\begin{array}{c}\% \\
(18.3) \\
\end{array}$ & $\begin{array}{c}n^{0} \\
(306)\end{array}$ & $\begin{array}{c}\% \% \\
(100.0) \\
\end{array}$ & 1 & 2 & & \\
\hline $\begin{array}{l}\text { Inadequate features/ negative } \\
\text { profile }(0 \leq 1 \text { positive picture } \\
\text { chosen })\end{array}$ & 83 & 33,2 & 20 & 35,7 & 103 & 33,7 &,- 4 &, 4 & \multirow{3}{*}{0,199} & \multirow{3}{*}{0,905} \\
\hline $\begin{array}{l}\text { Poorly adequate/ Risk profile } \\
\text { ( } 2 \text { or } 3 \text { positive pictures selected) }\end{array}$ & 31 & 12,4 & 6 & 10,7 & 37 & 12,1 &, 3 &,- 3 & & \\
\hline $\begin{array}{l}\text { Highly adequate features/ Positive } \\
\text { profile ( } 4 \text { to } 5 \text { positive pictures } \\
\text { selected) }\end{array}$ & 136 & 54,4 & 30 & 53,6 & 166 & 54,2 &, 1 &,- 1 & & \\
\hline
\end{tabular}


In order to complement the study, a multivariate analysis procedure, called multivariate decision trees, was performed. In such analysis, the CHAID algorithm, an acronym for Chi-Square Automatic Interaction Detector was used ( $c f$. Figure 2). The explanatory variables (also known as independent variables) used to design decision Tree 1, hereinafter represented, were the importance of assigning a Student Mentor to each student of an undergraduate course and the students' age. The Ideal Mentor's features were taken into account as a response variable (aka dependent variable).

The results exhibited in the decision tree show that there are 2 levels of depth whose variables are statistically significant in explaining the Ideal Mentor's features.

In the first box that represents node 0, or root node, the information about the Ideal Mentor's adequate features is highlighted. This level corresponds to the choice of $39.5 \%$ of the participants. However, and since the mean value assigned to the Ideal Mentor's poorly adequate features is approximately $33.0 \%$, there is evidence of a large proximity between both representative values.

At the first level of the depth of the decision tree, more precisely in relation to root node 1 , there is information about the participants' level of agreement with the importance of assigning a Student Mentor to each student of any undergraduate course. The CHAID method is used to highlight the adequate features of the ideal mentor student. $39.2 \%$ of the participants have selected the features they consider the best suited for their hypothetical student mentor. For participants who do not attach any sort of importance to the assignment of a student mentor to undergraduate students, root node 2, the CHAID method highlights the ideal mentor's inappropriate features. This position represents $43.9 \%$ of the participants' opinions and, therefore, reflects a statistically significant difference $\left(X^{2}=7,724 ; \mathrm{p}=0.021\right)$.

The second level of the depth of the decision tree, more specifically in root node 3 , includes the participants who are 19 or younger. The CHAID method highlights the percentage of participants who have favored a more appropriate profile for their Ideal Mentor, with a representativeness of $45.7 \%$. In root node, that expresses the preferences of participants who were 19 or older, the mean value concerning the inappropriate features of the Ideal Mentor is highlighted. This value represents $36.5 \%$ of the participants' responses and shows the existence of statistical significance between the two age groups $\left(X^{2}=9,440 ; \mathrm{p}=0.018\right)$.

Figure 2. CHAID tree 1-ideal mentor's features versus the assignment of a Student Mentor to each undergraduate student.

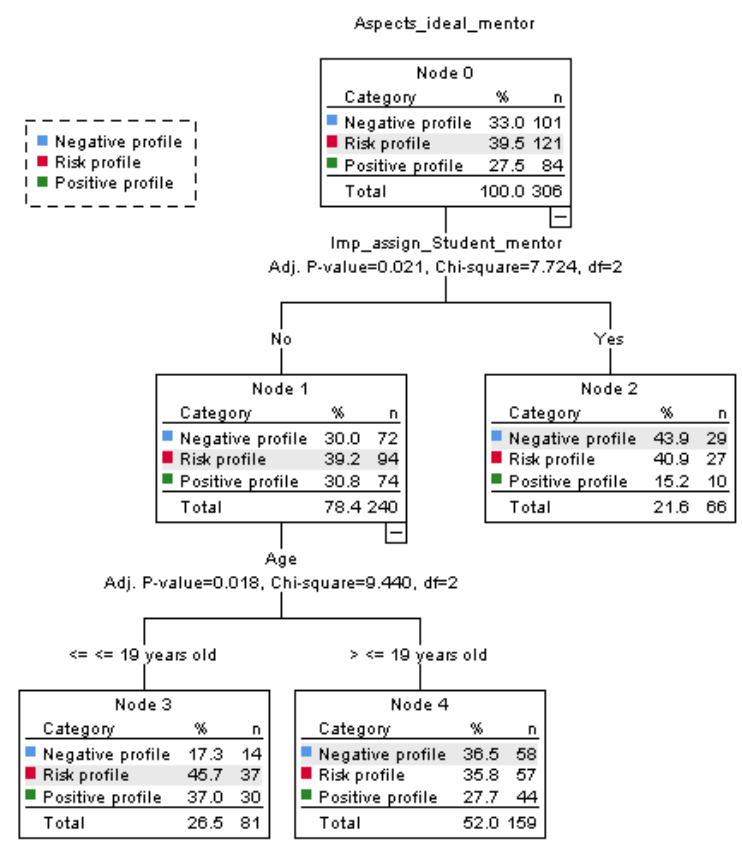

\section{Discussion}

Results confirm the importance of Student Mentors, older students who can help younger or first year higher education students so they are able to develop a sense of self-efficacy and find coping strategies that will help them minimize any negative feelings/emotions experienced during their first school days or during the whole course. As Carr, Perrell \& Recchia (2016) have pointed out, if students do not possess these skills, they may have problems adapting to the new and challenging events or situations they will have to face in their academic context. They same authors also emphasize that Student Mentors can negotiate with their Mentees an action plan whose aim will be to support the development of interpersonal skills, to provide them with human, academic, social and pedagogical support that will 
surely help them overcome any negative feelings/emotions caused by the demands of this new academic context. According to Karkowska (2015), the Student Mentor is a more experienced individual who is responsible for guiding and advising and who will foster the mentee's professional, academic or personal development. The study conducted by Jay, Park, Deirdre \& Doug (2016) is in agreement with what has been addressed before, for it claims that students with mentors show greater well-being and greater satisfaction with their academic life compared to students who are not mentees and who, consequently, do not have the support of a student mentor.

\section{Conclusions}

Findings revealed that the assignment of a Student Mentor to each undergraduate student is considered, as a whole, an important strategy. In addition, the participants in favor of such assignment claimed that it should take place in the 1 st year of the course $(47.1 \%)$. It was concluded that most participants, regardless of their gender, chose positive characteristics and a positive profile for their Ideal Mentor (54.2\%). The following features are considered to be the most positive: Satisfied (68\%), Tranquil (78.1\%); Optimistic (85\%); Confident (88.2\%) and Interested $(87.9 \%)$.

Results suggest the need for intervention programs that will implement concrete actions about the Student Mentors' role in the first year of the course so that students can understand how mentoring processes work and so they can figure the educational, pedagogical and social gains they can achieve if they are assigned a Student Mentor.

This initiative constitutes a personalized human support suited to respond to each student's uniqueness as it supports and encourages their interpersonal relationship with other colleagues and provides them with the chance to share relevant experiences, minimizing the newcomers' adjustment difficulties when they first arrive at a higher education institution. This kind of support will foster more positive emotions/feelings throughout the whole course. The existence of training programs to become a Student Mentor is another concern that has to be solved since those students will have to be prepared to be able to properly play the role they have been assigned: to act as catalysts for new students' integration, agents who will promote a culture of inclusion among higher education students and who will, therefore, contribute to the students' personal, academic and social, individual and collective well-being and whose action can, eventually, contribute to the mentees' good academic performance and to help prevent school failure and dropout in higher education.

\section{Acknowledgements}

The current project was funded by the FCT (Portuguese Foundation for Science and Technology) as part of the project "SuperES", Ref: PROJ/ CI\&DETS/ CGD/0005). We would like to express our sincere gratitude to the FCT, Superior School of Health, Polytechnic Institute of Viseu, Portugal.

\section{References}

Botas, A.L., Gabriel, G.\& Welling, H. (1997). Manual da Formação MENTORADO 1997/1998. SAP-IST.

Carr, J., Pitt, M., Perrell, E., \& Recchia, N. (2016). Mentoring students: exploring and managing incivil behaviour in community nursing placements. British Jour. of Community Nursing, 21(4), 203-207.

Cunha, M. (2017). Escala de Faces do Mentor Ideal. In M. Cunha (Coord.), Projeto supervisão e mentorado no ensino superior: Dinâmicas de sucesso (SuperEs). (Ref : Proj/CI\&DETS/CGD/005). Retrieved from http://www.ipv.pt/ci/projci/5.htm

Cunha, M. (Coord.). (2017). Projeto supervisão e mentorado no ensino superior: Dinâmicas de sucesso SuperES. (SuperEs). (Ref ${ }^{\mathrm{a}}$ : Proj/CI\&DETS/CGD/005). Retrieved from http://www.ipv.pt/ci/projci/5.htm

Cunha, M., Duarte, J., André, S., Sequeira, C., Castro-Molina, F.-J., Mota, M., ... \& Freitas, S. (2017). Bem-estar em estudantes do ensino superior. Millenium, 2 (ed espec 2), 21-38. https://doi.org/10.29352/mill0202e.02.

Jay, J.H., Park, P.A., Deirdre, D., \& Doug, M. (2016). The medical students' perspective of faculty and informal mentors: a questionnaire study. BMC Medical Education, 16, 4, 1-7.

Karkowska, M. (2015). MENTOR - Mentoring between teachers in secondary and high schools. Project number - 2014-1-PL01-KA200-003335. Retrieved from http://edu-mentoring.eu/handbook /supplement.pdf 